\title{
Effectively selecting aptamers targeted to aromatic biogenic amines and their application in aptasensing establishment
}

Nuo Duan, ${ }^{a}$ Mingqian Song, ${ }^{a}$ Weiyu Mi, ${ }^{a}$ Zhouping Wang, ${ }^{a}$ Shijia $W u{ }^{a b}$

${ }^{a}$ State Key Laboratory of Food Science and Technology, School of Food Science and Technology, International Joint Laboratory on Food Safety, Jiangnan University,

\author{
Wuxi 214122, China \\ ${ }^{b}$ Guangdong Laboratory for Lingnan Modern Agriculture, Guangzhou, 510642,
}

China

*To whom correspondence should be addressed

Tel: +8651085917023

Fax: +8651085917023

E-mail: wusj1986@163.com 


\section{Optimization of GO}

In order to achieve the best fluorescence quenching efficiency in the GO based fluorescent binding assay, GO concentration and GO/ssDNA incubation time, was optimized. Briefly, $100 \mu \mathrm{L}$ various concentrations of GO (i.e., 0.05, 0.15, 0.25, 0.35, and $0.45 \mathrm{mg} / \mathrm{mL}$ ) were added into microtubes containing a fixed concentration of 100 $\mu$ L FAM-labeled ssDNA (200 nM final concentration). The fluorescence intensities of the resulting mixture of FAM-labeled ssDNA and GO of different concentrations were measured in a 96-well plate using a Synergy H1 multi-detection microplate reader (BioTek Instruments, Inc., USA). In addition, different GO/ssDNA incubation times (i.e., $0,15,30,45$, and 60 min of quenching time) at $25^{\circ} \mathrm{C}$ were also studied. The results were shown in Fig. S4A, the maximum fluorescence quenching efficiency was obtained using a GO concentration of $0.25 \mathrm{mg} / \mathrm{mL}$, which was sufficient to quench the fluorescence signal of $200 \mathrm{nM}$ FAM-labeled ssDNA. This result demonstrates that the ssDNA library has been completely adsorbed by GO. In addition, the fluorescence polarization value increases almost linearly with the GO concentration and there is no maximal platform observed in the GO concentration range. Considering the good performance of experiment and the cost, $0.25 \mathrm{mg} / \mathrm{mL}$ of GO was chosen in the study. Besides, the optimal incubation time was determined by incubating $0.25 \mathrm{mg} / \mathrm{mL} \mathrm{GO}$ with the ssDNA library for different incubation times (i.e., $0,15,30,45$, and $60 \mathrm{~min}$ ). As shown in Fig. S4B, GO reacted with the ssDNA library and obtained minimum fluorescence intensity and maximum fluorescence polarization value within $30 \mathrm{~min}$. Therefore, a GO concentration of $0.25 \mathrm{mg} / \mathrm{mL}$ and a $\mathrm{GO} / \mathrm{ssDNA}$ incubation time of 30 min were used for the GO based binding assay.

\section{HPLC conditions for tyramine and $\beta$-phenylethylamine in real samples}

The HPLC conditions were conducted according to the previous work with some modification [1]. The HPLC analysis was performed with a HITACHI high performance liquid chromatograph (Chromaster, HITACHI, Japan). An Agilent Eclipse Plus C18 chromatographic column $(250 \mathrm{~mm} \times 4.6 \mathrm{~mm}, 5 \mu \mathrm{m})$ was employed 
for the chromatographic separation at $35^{\circ} \mathrm{C}$. A: ammonium acetate $(0.01 \mathrm{~mol} / \mathrm{L})$ and $\mathrm{B}$ : acetonitrile were used as the mobile phases. The detection was done at wavelength $254 \mathrm{~nm}$ at a flow rate of $0.8 \mathrm{~mL} / \mathrm{min}$, with injection volume $20 \mu \mathrm{L}$.

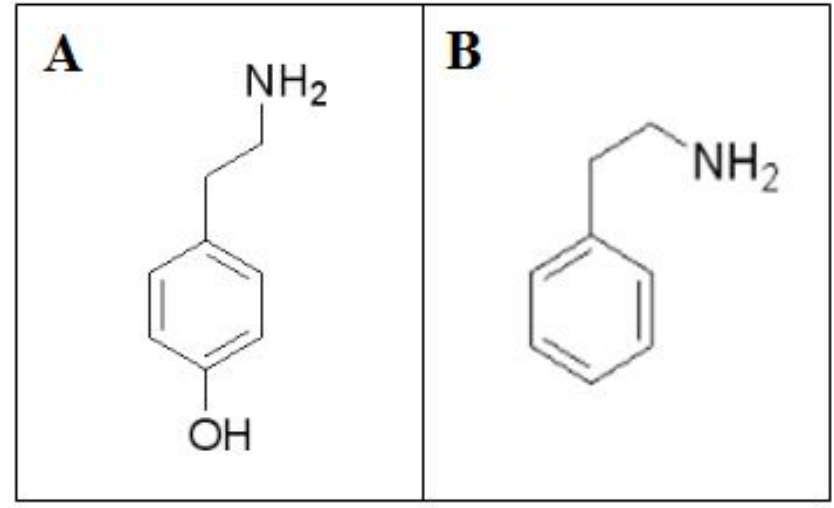

Fig. S1 Structures of tyramine (A) and phenylethylamine (B)

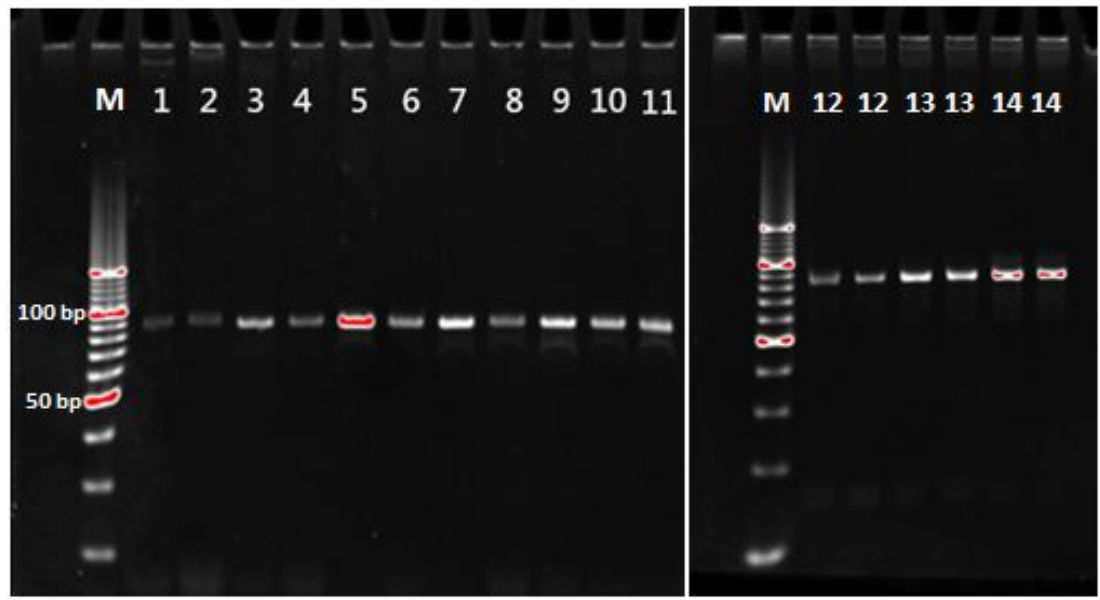

Fig. S2 PAGE results of dsDNA products by PCR in different selection rounds. Lanes M represent the DNA ladder, 1 11 represent 1 11 rounds in One-pot SELEX, 12 14 represent 12 14 rounds for tyramine and phenylethylamine in Separate SELEX, respectively. 


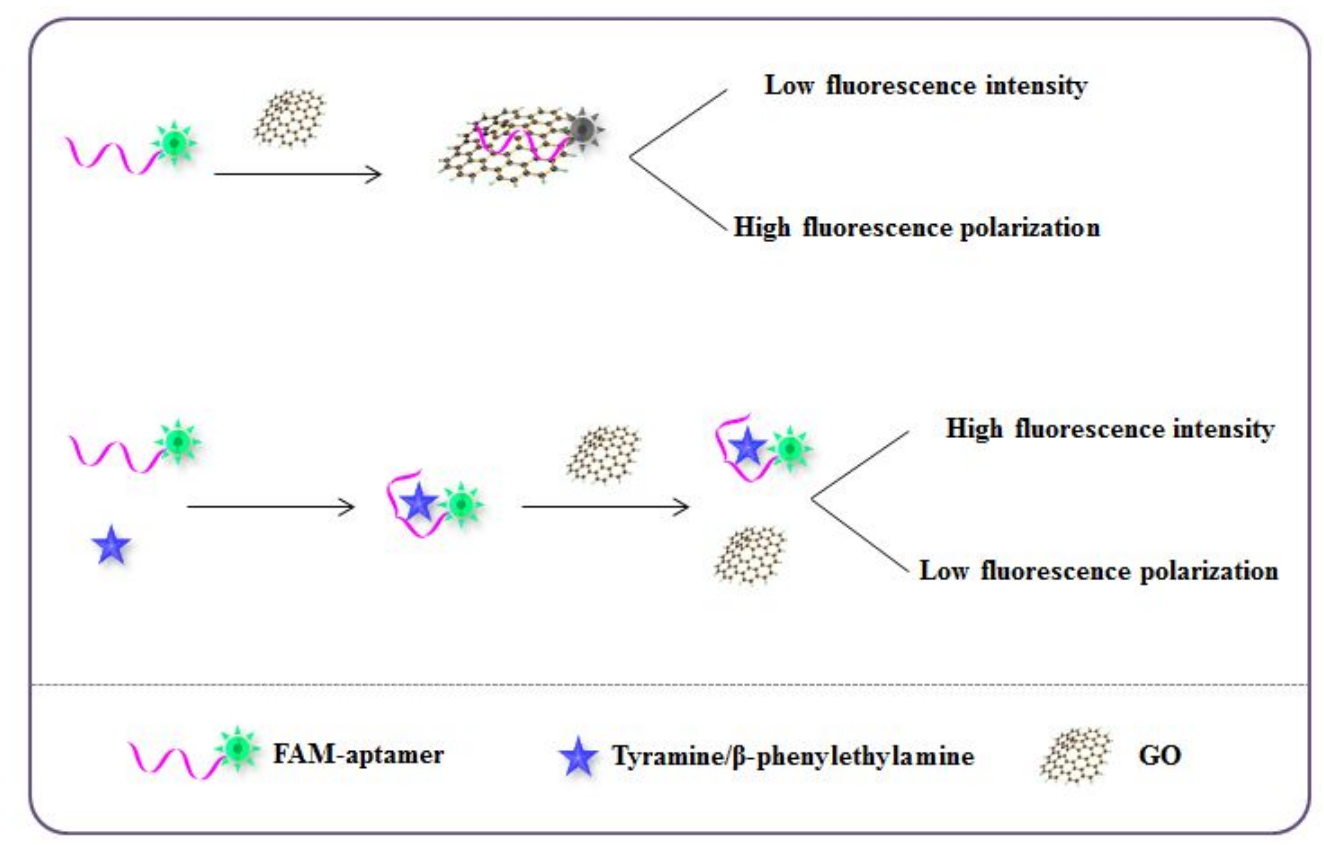

Fig. S3 Schematic illustration of GO-based binding analysis via fluorescence analysis and fluorescence polarization
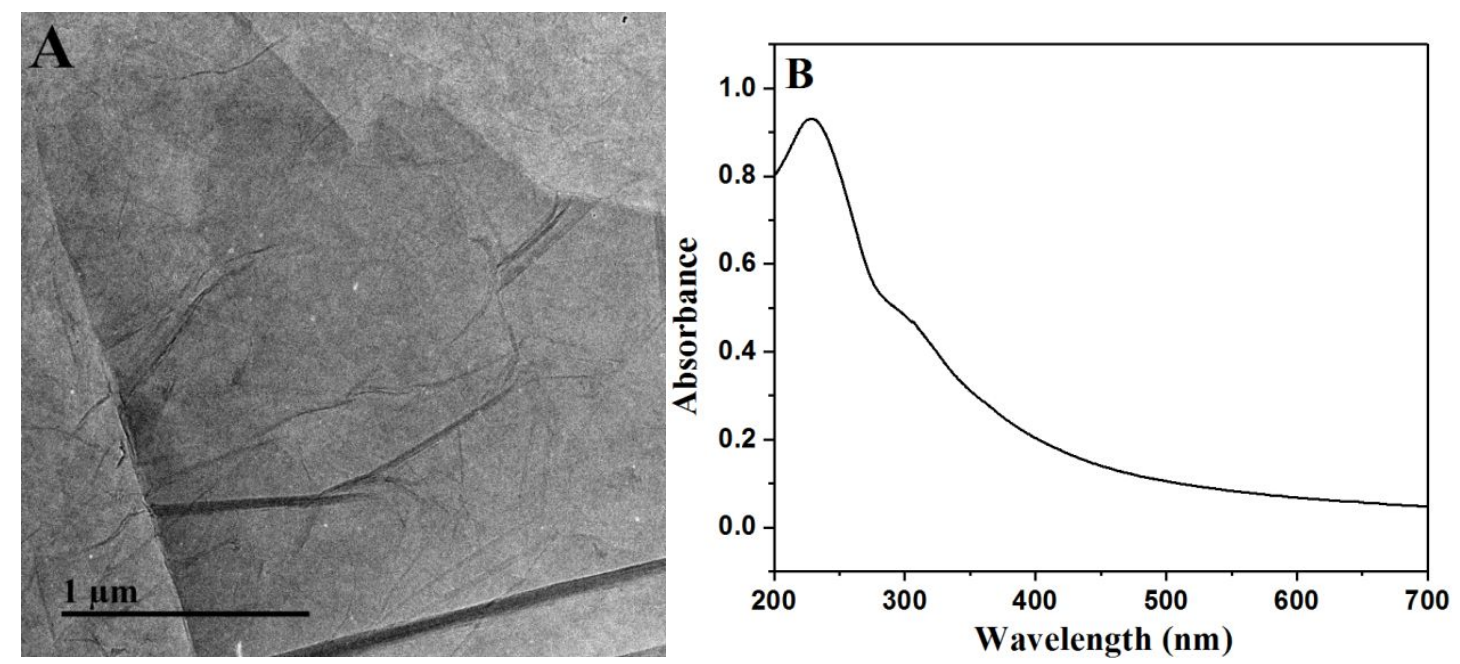

Fig. S4 TEM image (A) and UV/Vis spectrum (B) of GO 


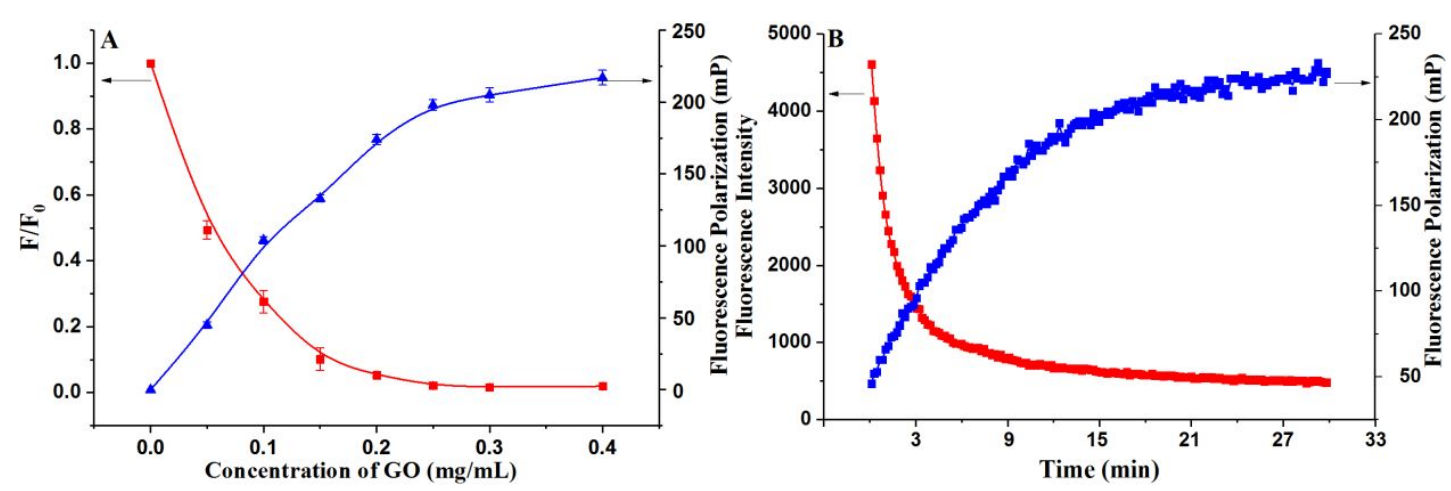

Fig. S5 Optimization of GO concentration (A) and GO/ssDNA incubation time (B)
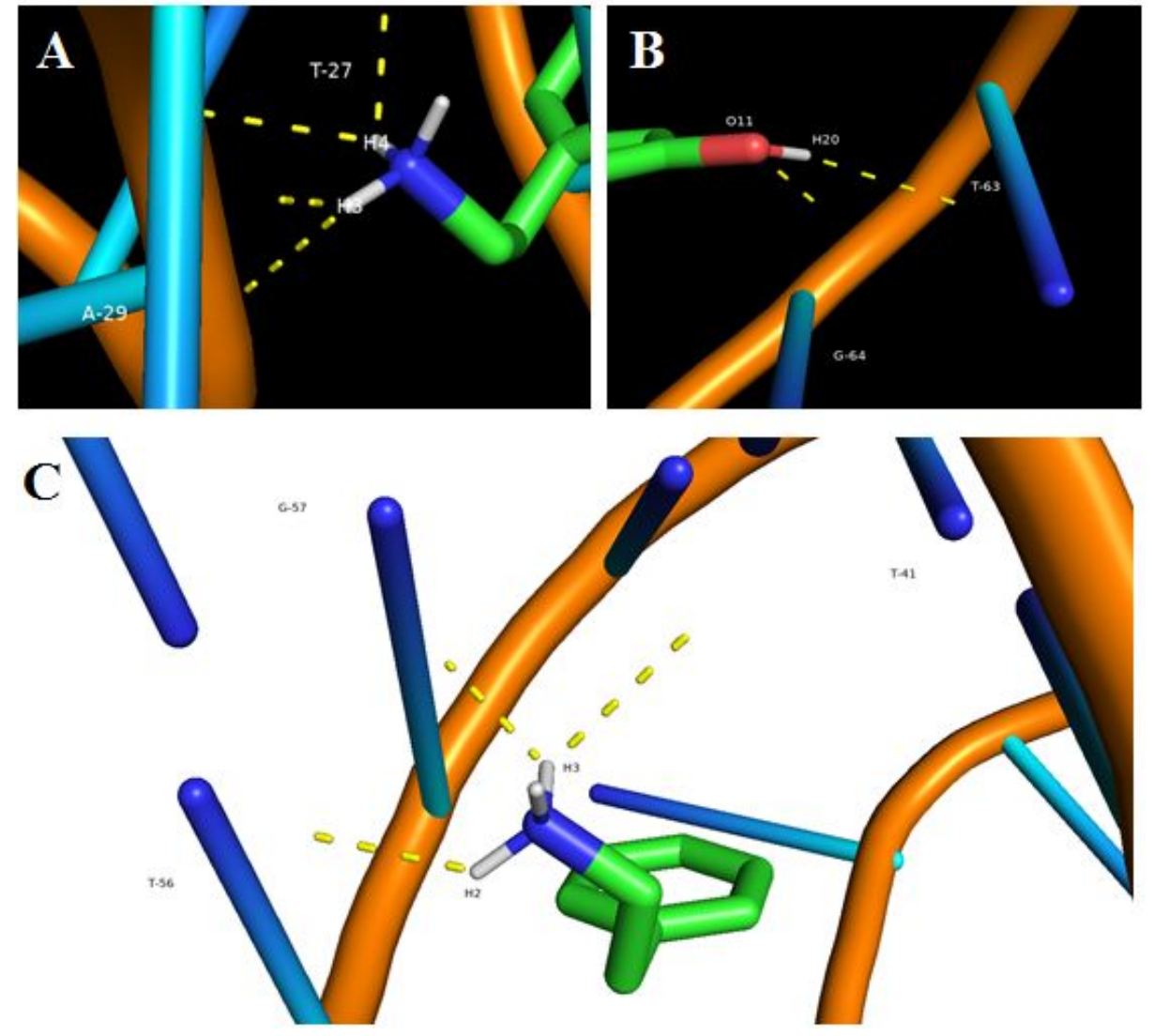

Fig. S6 The 3-D binding mode of T-27, A-29 (A) and T-63, G-64 (B) with TYR-2, T-41, T-56 and G-57 with PHE (C) 
Table S1. The conditions for One-pot aptamers selection

\begin{tabular}{cccccc}
\hline & & \multicolumn{2}{c}{ Counter SELEX } & \multicolumn{2}{c}{ Positive SELEX } \\
\cline { 3 - 6 } Round & ssDNA & Each Counter & Incubation & TYR+PHE & Incubation \\
& $(\mathbf{p m o l})$ & target $(\boldsymbol{\mu M})$ & time (min) & $(\boldsymbol{\mu M})$ & time (min) \\
\hline 1 & 1000 & - & - & $100+100$ & 120 \\
2 & 100 & - & - & $60+60$ & 120 \\
3 & 100 & - & - & $60+60$ & 120 \\
4 & 100 & 60 & 120 & $60+60$ & 120 \\
5 & 80 & - & - & $60+60$ & 120 \\
6 & 80 & - & - & $40+40$ & 90 \\
7 & 80 & 40 & 90 & $40+40$ & 90 \\
8 & 60 & - & - & $40+40$ & 90 \\
9 & 60 & 40 & 60 & $40+40$ & 90 \\
10 & 60 & - & - & $30+30$ & 90 \\
11 & 40 & - & - & $30+30$ & 60 \\
\hline
\end{tabular}

Table S2. The conditions for Separate aptamers selection

\begin{tabular}{cccccc}
\hline & & \multicolumn{2}{c}{ Counter SELEX } & \multicolumn{2}{c}{ Positive SELEX } \\
\cline { 3 - 6 } Round & ssDNA & Each Counter & Incubation & TYR/PHE & Incubation \\
& $($ pmol) & target $(\boldsymbol{\mu M})$ & time (min) & $(\boldsymbol{\mu M})$ & time (min) \\
\hline 12 & 40 & 30 & 40 & $30+30$ & 40 \\
13 & 40 & 30 & 40 & $30+30$ & 40 \\
14 & 40 & 30 & 30 & $30+30$ & 30 \\
\hline
\end{tabular}


Table S3. Comparison of analytical performance for the our fabricated aptasensor with other reported strategies for TYR and PHE detection

\begin{tabular}{|c|c|c|c|c|}
\hline BAs & Method & LOD & Food samples & Ref \\
\hline $\begin{array}{l}\text { TYR } \\
\text { PHE }\end{array}$ & HPLC & $0.06 \mathrm{mg} / \mathrm{L}$ & beer & 2 \\
\hline $\begin{array}{l}\text { TYR } \\
\text { PHE }\end{array}$ & $\begin{array}{l}\text { Capillary electrophoresis-tandem } \\
\text { mass spectrometry (CE-MS/MS) }\end{array}$ & $\begin{array}{l}2 \mu \mathrm{g} / \mathrm{L} \\
1 \mu \mathrm{g} / \mathrm{L}\end{array}$ & beer, wine & 3 \\
\hline TYR & $\begin{array}{l}\text { Capillary electrophoresis- } \\
\text { laser-induced fluorescence }\end{array}$ & $1.4 \mu \mathrm{g} / \mathrm{L}$ & beer & 4 \\
\hline $\begin{array}{l}\text { TYR } \\
\text { PHE }\end{array}$ & Surface Plasmon Resonance & $\begin{array}{l}10 \mathrm{nM} \\
90 \mathrm{nM}\end{array}$ & l & 5 \\
\hline TYR & ELISA & $2 \mathrm{ng} / \mathrm{mL}$ & fish & 6 \\
\hline TYR & Fluorescence immunoassay & $0.1 \mu \mathrm{g} / \mathrm{L}$ & pork, bacon... & 7 \\
\hline TYR & Molecularly imprinted-fluorescence & $5 \mu \mathrm{g} / \mathrm{kg}$ & fermented meat & 8 \\
\hline $\begin{array}{l}\text { TYR } \\
\text { PHE }\end{array}$ & Fluorescent aptasensor & $\begin{array}{l}0.34 \mathrm{ng} / \mathrm{mL} \\
0.39 \mathrm{ng} / \mathrm{mL}\end{array}$ & beer, pork & $\begin{array}{l}\text { This } \\
\text { work }\end{array}$ \\
\hline
\end{tabular}

\section{References}

[1] Fu, Q.Y.; Zheng, H.W.; Han, X.N.; Cao, L.M.; Sui, J.X., Development of a highly sensitive HPLC method for the simultaneous determination of eight biogenic amines in aquatic products. Acta Chromatographica 2021, 33, 378-386.

[2] Díaz-Liñán, M. C.; Lucena, R.; Cárdenas, S.; López-Lorente. A. I., Unmodified cellulose filter paper, a sustainable and affordable sorbent for the isolation of biogenic amines from beer samples. J Chromatogr A 2021, 1651, 462297.

[3] Daniel, D.; dos Santos, V. B.; Vidal, D. T. R.; do Lago, C. L., Determination of biogenic amines in beer and wine by capillary electrophoresis-tandem mass spectrometry. J Chromatogr A 2015, 1416, 121-128.

[4] Cortacero-Ramirez, S.; Arraez-Roman, D.; Segura-Carretero, A.; 
Fernandez-Gutierrez, A., Determination of biogenic amines in beers and brewing-process samples by capillary electrophoresis coupled to laser-induced fluorescence detection. Food Chem 2007, 100, 383-389.

[5] Bettini, S.; Syrgiannis, Z.; Pagano, R.; Dordevic, L.; Salvatore, L.; Prato, M.; Giancane, G.; Valli, L., Perylene Bisimide Aggregates as Probes for Subnanomolar Discrimination of Aromatic Biogenic Amines. ACS Appl Mater Inter 2019, 11, 17079-17089.

[6] Teepoo, S.; Promta, A.; Phapugrangkul, P., A Competitive Colorimetric Immunosensor for Detection of Tyramine in Fish Samples. Food Anal Meth 2019, 12, $1886-1894$.

[7] Zhang, B., Sheng, W., Liu, Y., Huang, N., Zhang, W.L., Wang, S., Multiplexed fluorescence immunoassay combined with magnetic separation using upconversion nanoparticles as multicolor labels for the simultaneous detection of tyramine and histamine in food samples. Anal Chim Acta 2020, 1130, 117-125.

[8] Zhang, D.W., Liu, H.L., Geng, W.T., Wang, Y.P., A dual-function molecularly imprinted optopolymer based on quantum dots-grafted covalent-organic frameworks for the sensitive detection of tyramine in fermented meat products. Food Chem 2019, 277, 639-645. 